\title{
Communication
}

\section{Synthesis of RP 48497, an Impurity of Eszopiclone}

\author{
Yu Sha ${ }^{1}$, Lei Zhang ${ }^{1}$, Gui-Jie Du ${ }^{2}$, Jian Ren ${ }^{1}$ and Mao-Sheng Cheng ${ }^{1, *}$ \\ ${ }^{1}$ Key Lab of New Drug Design and Discovery of Liaoning Province, School of Pharmaceutical \\ Engineering, Shenyang Pharmaceutical University, Shenyang 110016, P. R. China; \\ E-mails: shayu@syphu.edu.cn; zl.719@163.com; renjian_1981@hotmail.com \\ 2 Jinzhou Jiutai Pharmaceutical Co. Ltd, Jinzhou 121012, P.R. China; E-mail: duguijie@yahoo.com.cn \\ * Author to whom correspondence should be addressed: E-Mail: mscheng@syphu.edu.cn.
}

Received: 5 June 2008; in revised form: 8 August 2008 / Accepted: 12 August 2008 / Published: 22 August 2008

\begin{abstract}
RP 48497 is a photodegradation product of eszopiclone, a non-benzodiazepine sedative-hypnotic used in the treatment of insomnia. We report herein the first synthesis of RP 48497 via reduction, chlorination, and recyclization of 6-(5-chloropyridin-2-yl)-7hydroxy-6,7-dihydropyrrolo[3,4-b]pyrazin-5-one (3), a key intermediate in the synthesis of eszopiclone. The structure of RP 48497 was confirmed by its ${ }^{1} \mathrm{H}-\mathrm{NMR}$ and MS data. The mechanism of the reduction step in the synthesis of RP 48497 was also studied and the key parameters were determined. These findings should be important for quality control purposes in the manufacture of eszopiclone.
\end{abstract}

Keywords: RP 48497, eszopiclone, quality control

\section{Introduction}

Eszopiclone [(+)-6-(5-chloro-2-pyridinyl)-(7S)-(4-methylpiperazin-1-yl-carbonyloxy)-6,7-dihydro5H-pyrrolo[3,4-b]pyrazine-5-one, RP 27267, Estorra ${ }^{\circledR}$, Lunesta $\left.{ }^{\circledR}\right]$, the $(S)$-enantiomer of zopiclone, is more active and less toxic than the racemic zopiclone. It is metabolized by three major pathways, involving decarboxylation, oxidation and demethylation. The main urine metabolites are the less active 
eszopiclone- $N$-oxide (RP 29753) and the inactive $N$-desmethyleszopiclone (RP 32273). RP 29753 can also be considered as an impurity of eszopiclone and is formed by the oxidation of the latter. The related substance RP 29307 is formed during the penultimate phase of the synthesis. It may pre-exist in the starting material and it can also be formed by the hydrolysis of eszopiclone during storage. Finally, RP 48497 is a non-chiral potential photodegradation product whose formation is caused by bright light [1].

Figure 1. Structures of eszopiclone and its metabolites.<smiles>O=C(OC1c2nccnc2C(=O)N1c1ccc(Cl)cn1)N1CCNCC1</smiles>

Eszopiclone

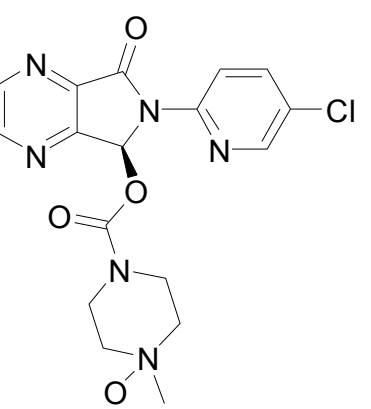

RP 29753<smiles>O=C(OC1c2nccnc2C(=O)N1c1ccc(Cl)cn1)N1CCNCC1</smiles>

RP 32273<smiles></smiles><smiles>[R]OC(=O)[O-]</smiles>

As syntheses of the other impurities of eszopiclone, except RP 48497, have been previously reported, the main aim of our work presented here was to synthesize this compound. This is significant for the quality control of eszopiclone, whose chemical synthesis as shown in Scheme 1 has been reported [2-5]:

Scheme 1. Synthetic route to eszopiclone.<smiles></smiles><smiles>CC(C)CC(=O)c1nccnc1C(=O)O</smiles>

1<smiles>O=C1c2nccnc2C(=O)N1c1ccc(Cl)cn1</smiles><smiles>CC(C)c1cnc2c(n1)C(O)N(c1ccc(Cl)cn1)C2=O</smiles><smiles>CC=CC</smiles><smiles>CN1CCN(C(=O)OC2c3nccnc3C(=O)N2c2ccc(Cl)cn2)CC1</smiles><smiles>CN1CCN(C(=O)O[C@H]2c3nccnc3C(=O)N2c2ccc(Cl)cn2)CC1</smiles>

(a) 5-Chloropyridin-2-ylamine, $\mathrm{CH}_{3} \mathrm{CN}$, reflux; (b) $\mathrm{Ac}_{2} \mathrm{O}$, reflux; (c) $\mathrm{KBH}_{4}$, 1,4-dioxane, $\mathrm{H}_{2} \mathrm{O}, 13$ ${ }^{\circ} \mathrm{C}$; (d) 4-methylpiperazine-1-carbonyl chloride hydrochloride, $\mathrm{Et}_{3} \mathrm{~N}$, pyridine, $\mathrm{CH}_{2} \mathrm{Cl}_{2}$, reflux; (e) tartaric acid or malic acid 


\section{Results and Discussion}

\section{Synthesis}

Our synthetic route to RP 48497 using the same starting materials as that to eszopiclone is illustrated in Scheme 2. Considering the instability of intermediate 3, its treatment with excess $\mathrm{KBH}_{4}$ or $\mathrm{NaBH}_{4}$ resulted in the cleavage of the carbon-nitrogen bond to yield compound 4. Finally, compound $\mathbf{5}$, obtained by the chlorination of $\mathbf{4}$, was intramolecularly cyclized without purification in the presence of $\mathrm{NaH}$ to form the target compound RP 48497 (6). The total yield was $40 \%$.

Scheme 2. Synthetic route to RP 48497.

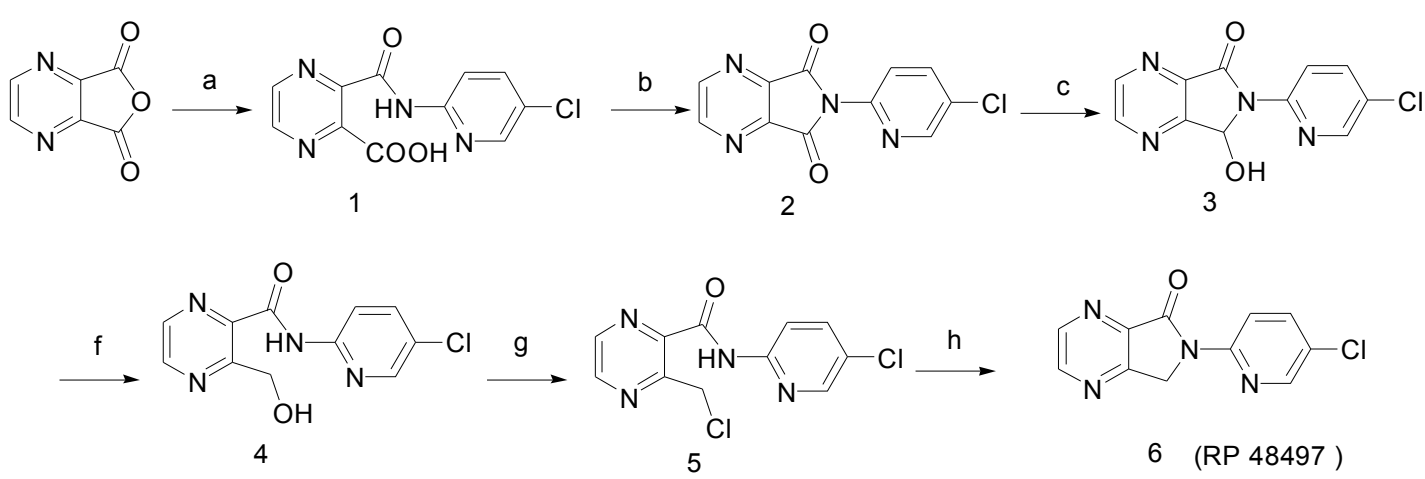

(a) 5-Chloropyridin-2-yl-amine, $\mathrm{CH}_{3} \mathrm{CN}$, reflux; (b) $\mathrm{Ac}_{2} \mathrm{O}$, reflux; (c) $\mathrm{NaBH}_{4}$, 1,4-dioxane, $\mathrm{H}_{2} \mathrm{O}, 13$

${ }^{\circ} \mathrm{C}$; (d) 4-methylpiperazine-1-carbonyl chloride hydrochloride, $\mathrm{Et}_{3} \mathrm{~N}$, pyridine, $\mathrm{CH}_{2} \mathrm{Cl}_{2}$, reflux; (e) tartaric acid or malic acid; (f) $\mathrm{NaBH}_{4}, 1,4$-dioxane, $\mathrm{H}_{2} \mathrm{O}$; (g) $\mathrm{CH}_{2} \mathrm{Cl}_{2}, \mathrm{SOCl}_{2}$; (h) $\mathrm{NaH}$, DMF

After studying in depth the reduction step, we found that the amount of reductant used played a vital role in the transformation of the intermediate 2 to the intermediate 3 . If more than 0.5 molecular equivalents of reductant were present in the reaction mixtures, a certain amount of a byproduct whose structure has been identified as compound $\mathbf{4}$ could be obtained, and the content of $\mathbf{4}$ would increase when either the reaction temperature or the ratio of the reductant were increased. The polarity of $\mathbf{3}$ and $\mathbf{4}$, according to TLC, therefore, it is very difficult to separate them and purify of $\mathbf{3}$ from $\mathbf{4}$. The mechanism of the transformation from 3 to 4 can be explained as shown in Scheme 3 [6]:

Scheme 3. Mechanism of formation of intermediate 4.

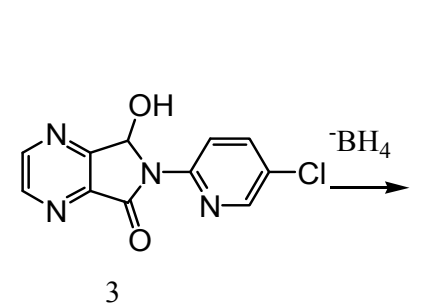<smiles></smiles><smiles>C[SbH2]O[C@H](CO)c1nccnc1C([O-])=Nc1ccc(Cl)cn1</smiles><smiles>O=C(Nc1ccc(Cl)cn1)c1nccnc1CO</smiles>

4

For this reason, the reduction of intermediate $\mathbf{2}$ to $\mathbf{3}$ is thus a key step in the preparation of eszopiclone. The content of compound $\mathbf{4}$ is a valid parameter for quality control of the intermediate $\mathbf{3}$. 
Since this impurity $\mathbf{4}$ is mixed with the intermediate $\mathbf{3}$, it could also be further acylated with 4methylpiperazine-1-carbonyl chloride hydrochloride during the process to give compound 7 (Scheme cheme 4), a ring-opening derivative of eszopiclone.

Scheme 4. Formation of compound 7.

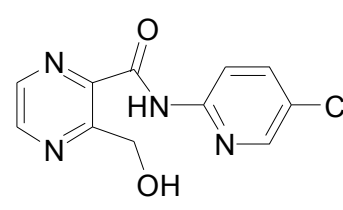

4

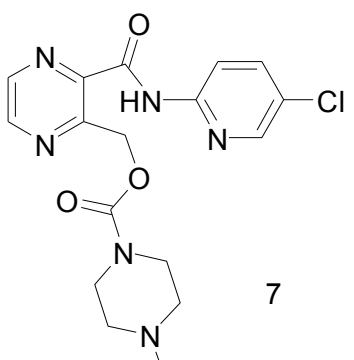

$\mathrm{N}$

(a) 4-Methylpiperazine-1-carbonyl chloride hydrochloride, $\mathrm{Et}_{3} \mathrm{~N}$, pyridine, $\mathrm{CH}_{2} \mathrm{Cl}_{2}$, reflux

Considering that it is very hard to remove compound $\mathbf{7}$ as a consequence of the similar polarities of eszopiclone and compound 7, it may be concluded that careful control on the reduction step to prevent the formation of compound $\mathbf{4}$ is important in the quality control of eszopiclone.

\section{Experimental}

\section{General}

All commercially available reagents and solvents were used without further purification, unless specified. Solvents were dried and re-distilled prior to use according to standard methods. Melting points are uncorrected and were determined on a Büchi Melting Point B-540 apparatus. ${ }^{1} \mathrm{H}-\mathrm{NMR}$ spectra were recorded on a Bruker ARX $300 \mathrm{MHz}$ instrument, using DMSO- $d_{6}$ as solvent and TMS as the internal standard. Coupling constants $(J)$ are expressed in Hz. Mass spectra were obtained on an Agilent 1100 mass spectrometer. Column chromatography (CC) was performed on silica gel H and analytical TLC on silica gel HF254.

\section{3-Hydroxymethyl-pyrazine-2-carboxylic acid (5-chloro-pyridin-2-yl)-amide (4)}

To a mixture of 1,4-dioxane $(230 \mathrm{~mL})$ and water $(12 \mathrm{~mL})$, was added 6-(5-chloropyridin-2-yl)-7hydroxy-6,7-dihydropyrrolo[3,4-b]pyrazin-5-one $(3,26.4 \mathrm{~g}, 0.10 \mathrm{~mol})$.. After cooling to $10{ }^{\circ} \mathrm{C}, \mathrm{NaBH}_{4}$ $(2.7 \mathrm{~g}, 0.07 \mathrm{~mol})$ was added to the above suspension. The mixture was stirred for 2 hours with the temperature kept between $10{ }^{\circ} \mathrm{C}$ to $15^{\circ} \mathrm{C}$ and then poured into ice/water $(300 \mathrm{~mL})$. Glacial acetic acid was added to adjust the $\mathrm{pH}$ to 5-6 and the mixture was stirred for 30 minutes. The precipitated solid was filtered and dried to give $20.0 \mathrm{~g}$ of a yellow product. Yield: $75.2 \%$; m.p.:176.0 ${ }^{\circ} \mathrm{C}-177.3{ }^{\circ} \mathrm{C} ;{ }^{1} \mathrm{H}$ NMR $\delta: 10.89(1 \mathrm{H}, \mathrm{s}), 8.84(1 \mathrm{H}, \mathrm{d}, J=2.31), 8.69(1 \mathrm{H}, \mathrm{d}, J=2.25), 8.45(1 \mathrm{H}, \mathrm{d}, J=2.43), 8.26(1 \mathrm{H}$, $\mathrm{d}, J=8.94), 8.03(1 \mathrm{H}, \mathrm{dd}, J=2.61,8.91), 5.34(1 \mathrm{H}, \mathrm{t}, J=5.91), 4.93(2 \mathrm{H}, \mathrm{d}, J=5.67)$. 
3-Chloromethylpyrazine-2-carboxylic acid (5-chloro-pyridin-2-yl)-amide (5)

To a $0{ }^{\circ} \mathrm{C}$ suspension of 3-hydroxymethylpyrazine-2-carboxylic acid (5-chloropyridin-2-yl)-amide $(4,30.0 \mathrm{~g}, 0.10 \mathrm{~mol})$ in dichloromethane $(120 \mathrm{~mL})$, thionyl chloride $(42 \mathrm{~mL})$ was added dropwise while keeping the temperature below $10{ }^{\circ} \mathrm{C}$. After the addition, the mixture was stirred at room temperature for 2 hours and then evaporated to dryness under reduced pressure. The off-white product was recrystallized from $i$-propane to give brown needles, 21.0 g. Yield: 65.4 \%; m.p.:149.0 ${ }^{\circ} \mathrm{C}-150.0$ ${ }^{\circ} \mathrm{C}$.

6-(5-Chloropyridin-2-yl)-6,7-dihydropyrrolo[3,4-b]pyrazin-5-one (RP 48497, 6)

To a $0{ }^{\circ} \mathrm{C}$ suspension of $\mathrm{NaH} 4.3 \mathrm{~g}(70 \%, 0.12 \mathrm{~mol})$ in DMF $(200 \mathrm{~mL}), 3$-chloromethylpyrazine-2carboxylic acid (5-chloropyridin-2-yl)-amide $(5,17.5 \mathrm{~g}, 0.06 \mathrm{~mol})$ was added slowly. After the addition, the reaction mixture was stirred for 24 hours at room temperature. Additional NaH (70 \%, 1.3 g, $0.04 \mathrm{~mol}$ ) was then added and the reaction mixture was stirred for another 1 hour. The mixture was poured into ice/water $(200 \mathrm{~mL})$. After the ice dissolved, the precipitated solid was filtered to give 11.8 $\mathrm{g}$ of a yellow powder. Yield: $77.2 \%$. The crude product can be further purified by CC (petroleum ether-EtOAc, 10:1); m.p.: $222.0{ }^{\circ} \mathrm{C}-224.0{ }^{\circ} \mathrm{C} ;{ }^{1} \mathrm{H}-\mathrm{NMR} \delta: 8.90(2 \mathrm{H}, \mathrm{d}, J=2.60), 8.60(1 \mathrm{H}, \mathrm{d}, J=9.00)$, $8.57(1 \mathrm{H}, \mathrm{d}, J=2.58), 8.08(1 \mathrm{H}, \mathrm{dd}, J=8.97,2.64), 5.13(2 \mathrm{H}, \mathrm{s}) ; \mathrm{MS} \mathrm{m} / \mathrm{z}: 47.2[\mathrm{M}+\mathrm{H}]^{+}, 269.1$ $[\mathrm{M}+\mathrm{Na}]^{+}, 514.9[2 \mathrm{M}+\mathrm{Na}]^{+}, 245.0[\mathrm{M}-\mathrm{H}]^{-}$.

\section{References}

1. Piperak, S; Parissi-Poulou, M. Enantiomeric separation of zopiclone, its metabolites and products of degradation on a cyclodextrin bonded phase. J. Chromatogr. A. 1996, 729, 19-28.

2. Cotrel, C.; Jeanmart, C.; Messer, M. N. Pyrrolo[3,4-b]pyrazine derivatives. U.S. Pat. 3,862,149, 1975.

3. Cotrel, C.; Jeanmart, C.; Messer, M. N.; Crisan, C. Heterocyclic compounds. U.S. Pat. 4,220,646, 1980.

4. Chen, HC; Liu ZZ; Zhang, CX. Synthesis of sedative hypnotic Zopiclone. J. Zheng Zhou Univ. (zirankexueban). 1993, 12, 73-76.

5. Zhang, YF; Zuo, DS; Tian, KP; Shen, JM. Synthesis of the new sedative hypnotic Zopiclone. Chin. J. Med. Chem. 1994, 4, 62-64.

6. Horii Z., Iwata C., Tamura Y. Reduction of phthalimides with sodium borohydride. J. Org. Chem. 1961, 26, 2273-2276.

Sample Availability: Samples are available from the authors.

(C) 2008 by the authors; licensee Molecular Diversity Preservation International, Basel, Switzerland. This article is an open-access article distributed under the terms and conditions of the Creative Commons Attribution license (http://creativecommons.org/licenses/by/3.0/). 